\title{
Promoção da saúde pública e proteção dos direitos fundamentais: a COVID-19 à luz das repercussões jurídico-constitucionais e jurídico- administrativas em Portugal
}

Promotion of public health and protection of fundamental rights: COVID-19 and its constitutional and administrative reflections in Portugal

Promoción de la salud pública y protección de los derechos fundamentales: COVID-19 y sus reflejos jurídico-constitucionales y jurídico-administrativos en Portugal

Ana Raquel Gonçalves Moniz ${ }^{1,2}$

\section{Resumo}

O presente texto tem como objetivo avaliar os reflexos da COVID-19 no Direito Constitucional e no Direito Administrativo, no âmbito do sistema jurídico português, considerando a necessária articulação entre a promoção da saúde pública e a tutela dos direitos fundamentais. Partindo do pressuposto do papel relevante desempenhado pela Administração Pública na concretização dos bens e valores constitucionais, analisa-se sucessivamente o impacto da pandemia na criação e operacionalização do direito da excecionalidade, bem como no controlo judicial dirigido à tutela dos direitos fundamentais comprimidos. Conclui-se que a excecionalidade das circunstâncias volta a exigir reflexões que tocam o âmago do próprio Estado de direito e, com toda a probabilidade, determinará a elaboração de diplomas especificamente destinados à prevenção e combate de crises sanitárias.

\section{Palavras-chave}

COVID-19. Saúde pública. Direito da saúde. Direitos civis.

\section{Abstract}

This text aims to evaluate the consequences of COVID-19 in Constitutional Law and Administrative Law, within the framework of the Portuguese legal system, by considering the necessary connection between the promotion of public health and the protection of fundamental rights. Working on the assumption that Public Administration plays a relevant role concerning the implementation of constitutional goods and values, the article analyzes the impact of the pandemics on the creation and the application of the law of the exception, as well as the available remedies for breach of the limited fundamental rights. At last, one may conclude that the exceptional circumstances demand deep reflections on the core of the rule of law and will probably require the preparation of statutes specifically designed to prevent and fight sanitary crises.

\section{Keywords}

COVID-19. Public health. Health law. Civil rights.

\footnotetext{
1 Doutora em Direito, Instituto Jurídico, Faculdade de Direito, Universidade de Coimbra, Coimbra, Portugal; Professora Associada, Faculdade de Direito, Universidade de Coimbra; Coimbra, Portugal. https://orcid.org/0000-0003-3770-8566. Email: anamoniz@fd.uc.pt; uc36584@uc.pt

${ }^{2}$ Este artigo faz parte do projeto "Responsabilidade em Saúde Pública no Mundo Lusófono: Fazendo Justiça durante e além da Emergência da Covid" - WHO ERC number - (CERC.0079/ HEG 70) - da iniciativa da OMS/Ética em Epidemia e foi financiada por FCDO/Wellcome Grant 214711/Z/18/Z.
} 


\section{Resumen}

El texto se destina a avaliar las consecuencias de la COVID-19 en el Derecho Constitucional y en el Derecho Administrativo, en la moldura normativa del sistema jurídico portugués, considerando la necesaria articulación entre la promoción de la salud pública y la tutela de los derechos fundamentales. Considerando el papel relevante de la Administración Pública para la implementación de los bienes y de los valores constitucionales, el artículo examina el impacto de la pandemia en la creación y la aplicación del derecho de excepción, y la existencia de mecanismos judiciales de protección de los derechos fundamentales comprimidos. A partir de estas consideraciones se puede concluir que las circunstancias excepcionales requieren reflexiones que atingen el amago del Estado de derecho y exigen la preparación de leyes específicamente dedicadas a la prevención y combate de crises sanitarias.

\section{Palabras clave}

COVID-19. Salud pública. Derecho de la salud pública. Derechos civiles.

\section{Introdução}

A tutela do bem jurídico-constitucional saúde pública e a sua epitomização num direito (objetivo) da saúde demonstrou a respetiva transversalidade (ou horizontalidade) e, no contexto do combate à pandemia, penetrou todas as dimensões normativo-sociais (1) e todos os ramos jurídico-dogmáticos ${ }^{3}$. Todavia, talvez nenhuma matéria venha sentindo (pelo menos, com esta crescente intensidade) os influxos causados pela crise pandémica como os direitos fundamentais e o(s) modo(s) como a Administração se confronta com a sua realização - com todas as repercussões que tal determina quer no Direito Constitucional, quer no Direito Administrativo. Tal resultou não só da circunstância de o cerne das preocupações dos poderes públicos se concentrar na realização do direito à proteção da saúde (e do impacto nos serviços de saúde, enquanto mecanismo privilegiado dessa proteção), mas também (e como uma importância absolutamente não despicienda) do facto de a garantia da saúde pública e as medidas de prevenção e combate à COVID-19 haverem implicado uma afetação de diversos direitos fundamentais.

Neste horizonte, a convocação do(s) instituto(s) do estado de exceção representou um problema transversal a vários ordenamentos jurídico-constitucionais de matriz ocidental. As dificuldades têm, aqui e além, emergido nos vários Estados, assistindo-se a um crescendo no que tange à reação jurisdicional dirigida pelos titulares dos direitos contra as diversas medidas adotadas ao abrigo do(s) estado(s) de exceção declarado(s). As questões agudizam-se, sobretudo quando consideramos que a operacionalização normativa, mas

\footnotetext{
${ }^{3}$ Aliás, as circunstâncias atuais demonstram, com clareza, uma certa autonomia do direito da saúde, enquanto implica uma compreensão diferente ou renovada a institutos jurídicos já estabilizados (2), atingindo, sob a nossa perspetiva interessada (embora não exclusivamente, em virtude da interdisciplinaridade predicativa do direito da saúde), no âmago do Direito Constitucional e do Direito Administrativo.
} 
também individual e concreta, das medidas de prevenção e combate à pandemia decorreu, sobretudo (ainda que não exclusivamente) de atuações jurídico-administrativas, que operacionalizaram restrições jusfundamentais várias.

\section{O pressuposto: a Administração Pública como atora dos direitos fundamentais... em todos os cenários; em particular, a saúde como tarefa pública}

O entendimento segundo o qual Administração deve ter acesso direto à Constituição exige que esta se compreenda como adequado intérprete das normas constitucionais, bem como da respetiva realização no caso concreto.

A subordinação constitucional da atividade administrativa (o princípio da constitucionalidade da Administração) atinge a respetiva sublimação quando se considera que a perceção da Constituição como higher law leva, de alguma forma, ínsita a ideia de que cabe àquela definir os fundamentos axiológicos-jurídicos em que repousa, em termos mais próximos ou mais longínquos, a ação da Administração Pública. Eis-nos diante de uma ideia que se reveste de particular importância no contexto da promoção dos direitos fundamentais.

O «constitucionalismo administrativo» (3) constitui uma particular expressão do princípio da constitucionalidade da Administração, que, no seio da doutrina anglo-saxónica (em especial, norte-americana), defende o "acesso direto" à Constituição pela Administração, cometendo a esta última responsabilidades ativas no que tange à interpretação e implementação dos princípios e imperativos constitucionais ${ }^{4}$. Trata-se de uma conceção que, visando sublinhar o radical democrático e a legitimação do poder administrativo (5) e intercedendo sobre as questões atinentes ao papel (aos papéis) desempenhado(s) pela Administração (6), toca a dinâmica das relações entre poderes (poder constituinte e poderes constituídos, e, dentro destes, poder legislativo, poder judicial e poder administrativo), das relações entre «fontes de direito» (Constituição e lei) mobilizadas pela Administração e das relações entre ramos jurídico-dogmáticos (Direito Constitucional e Direito Administrativo, tomado este em sentido estrito, como ordinary administrative law) (6).

Não se trata, neste momento, de defender apenas a subordinação do agere administrativo à Constituição e aos direitos fundamentais, mas, muito para além disso, exige-

\footnotetext{
${ }^{4}$ Lee (4) sugere justamente que o punctum saliens do administrative constitutionalism não reside na afirmação da subordinação administrativa à Constituição, funcionando esta como limite (negativo) da atuação da Administração, mas antes na autonomia da interpretação e da implementação administrativas da Constituição e no modo como estas duas tarefas se refletem na ideia do government by Constitution.
} 
se da Administração uma postura positiva e, sobretudo, ativa no dever de ter em conta a Constituição no exercício da sua atividade, ou, se se preferir, no dever de implementar as opções constitucionais (constitutional enforcement). A esta perspetiva não é estranha a compreensão $(7,8)$ da função administrativa como realização do interesse público no quadro do direito.

A um primeiro nível, o constitutional enforcement pode resultar da adoção de mecanismos intradministrativos de autocontrolo (decorrentes da organização interna de uma entidade ou da emanação de normas regulamentares) que, orientando o exercício da discricionariedade, (auto)vinculem a Administração a agir de forma constitucionalmente comprometida - um aspeto particularmente relevante em cenários (como o atual) caracterizados pelo protagonismo do Executivo e da Administração (cf., infra, 3.2.). Num plano mais aprofundado, e sem deixar de acentuar o imediato relevo que esta conceção reveste no contexto da concretização de políticas públicas, a doutrina norte-americana chega a encará-la sob a ótica da Administração como defensora da Constituição, sublinhando que, em comparação com os tribunais, aquela se encontra em condições muito mais favoráveis para tutelar os valores constitucionais: com efeito, assumindo uma postura proativa na definição de políticas, as entidades administrativas (sobretudo estas são autoridades reguladoras independentes) assumem-se como primeiras instâncias do controlo (da aplicação) daquela regulação, podendo ainda ponderar (to balance) opções políticas diversas (ponderação que, naturalmente, escapa ao poder judicial), e devendo escolher aquela que melhor satisfaça os valores constitucionais em presença, sem que, por sua vez, tal signifique o afastamento das disposições legislativas sobre a matéria. Como adequadamente salienta Metzger (9), o desenvolvimento de um Estado administrativo com tarefas ativas na realização da Constituição não corresponde a qualquer perversão do modelo constitucional, mas antes assume-se como um dos seus desenvolvimentos primordiais.

Estas considerações revestem-se de uma acutilância especial quando se considera que a proteção da saúde e a tutela e promoção da saúde pública constituem tarefas públicas, concretizadas (juridicamente) através de instrumentos de direito público. Com efeito, a prestação de cuidados de saúde corresponde ao exercício daquilo que Marcello Caetano denominava "função técnica do Estado», i. e., o conjunto de atividades que, correspondendo de igual modo ao exercício da função administrativa enquanto dirigida à prossecução do interesse público, tem por núcleo a realização de atividades (produção de bens ou prestação 
Os direitos fundamentais: da normalidade à exceção

O cenário atual coloca-nos perante a necessária distinção entre situações de normalidade e situações de exceção, ou, numa outra perspetiva, entre o «direito da normalidade» e o "direito da crise» (15). Perante circunstâncias extraordinárias, assiste-se à emergência de um "direito oculto" ou de um "direito alternativo", até aí deixado "na sombra" (ou "na outra dimensão"), ao qual preside a satisfação ou tutela de valores ou interesses (desde logo, públicos) e que permite a adoção de soluções vedadas pela "legalidade normal" (16). A reação perante tais circunstâncias socorre-se de abordagens diferenciadas, que correspondem a tipologias diversas de estados de exceção, entre as quais se destaca a contraposição entre o modelo constitucional (corporizado num «direito constitucional de exceção») e o modelo legislativo (reconduzível a um «direito ordinário de emergência») (17).

No caso português, o combate à pandemia conduziu à mobilização de instrumentos jurídicos de excecionalidade, quer do estado de exceção constitucional (como sucedeu com o estado de emergência), quer dos "estados de exceção administrativos" (especiais) (18) decorrentes da Lei de Bases da Proteção Civil (LBPC) e da Lei de Bases da Saúde (LBS), em articulação com a Lei do Sistema de Vigilância em Saúde Pública (LVSP). Em geral, e quando concebidas como formas de "estado de necessidade", estas figuras consubstanciam um modo de legalização de atuações que, praticadas sob outro circunstancialismo, seriam inválidas, em cenários de perigo iminente e/ou atual para interesses superiores aos sacrificados, perigo esse não imputável ao autor da lesão. Uma eventual autonomização do estado de exceção constitucional assinalará a especificidade dos respetivos efeitos que possuem uma índole não meramente justificadora, mas verdadeiramente modificadora da ordem jurídico-constitucional própria da «normalidade» e, nessa medida, instituidora de uma "ordem constitucional alternativa" $(20,21)$ (e não apenas de uma “legalidade alternativa").

Se, evidentemente, a adoção de cada um dos estados de exceção referenciados depende do preenchimento de pressupostos próprios e possui uma duração (em parte) diferenciada, também da perspetiva da afetação dos direitos fundamentais, os respetivos efeitos são distintos. Se os estados de exceção constitucional conduzem, no sistema jurídico português, à possibilidade de suspensão do exercício de direitos fundamentais, as restantes hipóteses apenas admitem a respetiva restrição - em consonância (pelo menos, tendencial) com a gravidade das situações que lhes estão subjacentes. Neste horizonte, torna-se, por isso, premente a construção de uma "dogmática jusfundamental da(s) crise(s)" (22), que 


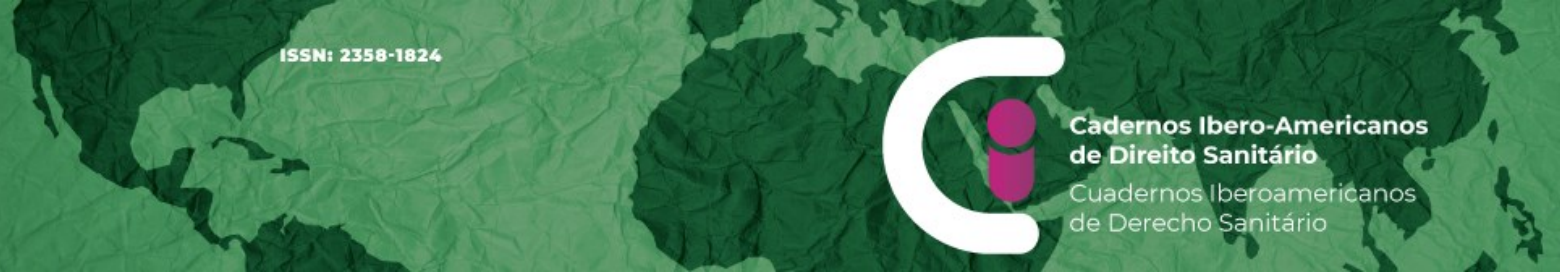

do Presidente, permitindo-Ihe suspender temporariamente direitos fundamentais, sem o concurso efetivo de qualquer outro órgão de soberania. Neste horizonte, o punctum crucis reside, pois, no desenho procedimental que precede a declaração presidencial do estado de emergência [a qual depende de audição do Governo e de autorização da Assembleia da República, nos termos dos artigos $138 .^{\circ}, 161 .^{\circ}$, alínea I), e 197..$^{\circ}$ n. ${ }^{\circ} 1$, alínea $f$ ), da $\mathrm{CRP}^{7}$ ], mas também no controlo parlamentar da sua específica execução [cf. artigo $162 .^{\circ}$, alínea b), da $\mathrm{CRP}^{8}$ ]. Ademais, também o esquema constitucional de organização do poder político (incluindo os órgãos de governo próprio das regiões autónomas) representa uma matéria que permanece intocada com a declaração de estado de sítio ou de estado de emergência (cf. artigo $19 .^{\circ},{ }^{\circ}{ }^{7}$, da CRP).

Por outro lado, importa acentuar que o regime do estado de exceção constitucional também apresenta limites materiais. Desde logo, e sem prejuízo da imprescindível observância das exigências de sentido do princípio da proporcionalidade (cf., em especial, artigo $19 .^{\circ}$, n. os 4 e 8 , da CRP) e do princípio da excecionalidade e limitação da suspensão (31), o n. ${ }^{\circ} 6$ do artigo $19 .^{\circ}$ da Lei Fundamental impede a suspensão dos direitos à vida, à integridade pessoal, à identidade pessoal, à capacidade civil e à cidadania, à não retroatividade da lei penal, do direito de defesa dos arguidos e da liberdade de consciência e de religião ${ }^{9}$; estamos, pois, diante de direitos que gozam de um regime de tutela reforçada ${ }^{10}$, permitindo a sua referência como «direitos fundamentalíssimos» (23) ou «direitos fundamentais absolutos» (21).

A par e independentemente deste regime muito específico, o ordenamento português conhece um conjunto de disposições que admite a adoção de medidas de excecionalidade em circunstancialismos muito díspares (nem todos associados - rectius, independentemente

\footnotetext{
${ }^{7}$ Recorde-se que o artigo 48 da Constituição alemã de 1919 determinava que, em caso de perturbação da ou perigo para a segurança e ordem pública, o Presidente poderia adotar as medidas que considerasse necessárias para o respetivo restabelecimento, eventualmente com o auxílio das forças armadas, admitindo ainda que, com este objetivo se suspendessem temporariamente, no todo ou em parte a liberdade, a inviolabilidade do domicílio e da correspondência, liberdade de expressão, direito de reunião, direito de associação, e a garantia de expropriação com indemnização. O Presidente encontrava-se ainda vinculado a dar conhecimento ao Reichstag daquelas medidas, detendo este órgão o poder de exigir a sua revogação. Schmitt (25) entendia este preceito à luz do conceito de kommissarische Diktatur - conceito que havia densificado em obra anterior, inspirado quer pela magistratura romana introduzida no início da República, quer pela teorização de Bodin, e que ainda corresponderia ao exercício de um poder constituído (e não ainda de um poder constituinte, como sucederia na ditadura soberana) (29).

${ }^{8} \mathrm{Cf}$. também artigo $28 .^{\circ}$ do RESEE.

${ }^{9}$ A estes direitos, o RESEE acrescenta o respeito pelas garantias do princípio da igualdade e da não discriminação, o direito de habeas corpus, a impossibilidade do estabelecimento de censura prévia, o direito de reunião dos órgãos estatutários dos partidos políticos, sindicatos e associações profissionais [cf. artigo $2 .^{\circ}$, proémio e n. ${ }^{\circ} 2$, alíneas a), d) e e)] e o direito de acesso aos tribunais para defesa dos direitos, liberdades e garantias (artigo 6. ${ }^{\circ}$ ). A este elenco exemplificativo (21) acrescem os direitos e liberdades naturalmente associados aos consagrados naquele elenco, na medida em que consubstanciam a sua expressão natural e lhes conferem a garantia de que carecem (31).

${ }^{10} \mathrm{Cf}$. também artigo $28 .^{\circ}$ do RESEE.
} 
da sua associação - à proteção da saúde pública). Eis o que sucede com os instrumentos decorrentes da LBPC: as declarações de situação de alerta, de contingência ou de calamidade, previstas neste diploma, consistem em mecanismos destinados, em geral, a atenuar os riscos coletivos e limitar os seus efeitos no caso de ocorrência de acidente grave ou de catástrofe (cf. artigo $1 .^{\circ}$ da LBPC) ${ }^{11}$, pressupondo um crescendo na gravidade da ocorrência, projetada na intensidade das medidas a adotar e no órgão com competência para as emitir (cf. artigos 8. $.^{\circ}, 9^{\circ}, 13 .^{\circ}$ e seguintes, da LBPC). Em particular, os atos jurídicos e as operações materiais praticados ao abrigo da declaração de situação de calamidade e com o propósito de lhe dar execução presumem-se praticados em estado de necessidade (cf. artigo $23 .^{\circ}, \mathrm{n} \cdot{ }^{\circ}$ 2, da LBPC) e podem envolver limitações a direitos fundamentais, como a propriedade privada ou a livre iniciativa económica privada (cf. artigos $23 .^{\circ}, \mathrm{n} .^{\circ} 1$, e $24 .^{\circ}$, da LBPC).

No contexto de crises de saúde pública, o artigo $17 .^{\circ}$ da LVSP pública confere poderes extensos ao membro do Governo responsável pela área da saúde. Ao contrário do que parece sugerir a respetiva epígrafe ("poder regulamentar excecional”), este preceito contempla medidas de exceção que não se reconduzem apenas à emissão de regulamentos, envolvendo aquela norma uma habilitação genérica para a prática de atos administrativos que impliquem a restrição, a suspensão ou o encerramento de atividades, a separação de pessoas que não estejam doentes, meios de transporte ou mercadorias que tenham sido expostos, de forma a evitar a eventual disseminação da infeção ou contaminação. Tal significa, pois, que, ao abrigo deste preceito, pode o Governo adotar medidas (primárias?) restritivas de direitos fundamentais, atingindo, v. g., a liberdade de deslocação, o direito de reunião ou a livre iniciativa económica privada.

A necessidade de debelar a pandemia originou, em Portugal, quer a declaração do estado de emergência (com fundamento em calamidade pública, configurando um "estado de necessidade interno" (34)) nos termos do artigo $19 .^{\circ}$ da CRP, quer a declaração de calamidade prevista na LBPC, quer a adoção de medidas de exceção fundamentadas em razões de saúde pública. Todavia, a mobilização destes instrumentos revelou algumas perplexidades, demonstrando que, em parte, o nosso sistema jurídico não dispunha de

\footnotetext{
${ }^{11}$ Nos termos do artigo $3 .^{\circ}$ da LBPC, o conceito de acidente grave reconduz-se a um "acontecimento inusitado com efeitos relativamente limitados no tempo e no espaço, suscetível de atingir as pessoas e outros seres vivos, os bens ou o ambiente", enquanto a catástrofe constitui um "acidente grave ou a série de acidentes graves suscetíveis de provocarem elevados prejuízos materiais e, eventualmente, vítimas, afetando intensamente as condições de vida e o tecido socioeconómico em áreas ou na totalidade do território nacional".
} 
mecanismos totalmente adequados para reagir perante uma crise pandémica, e que, noutra parte, a respetiva convocação ou aplicação prática originou dúvidas (em algumas hipóteses, severas) de constitucionalidade.

Assim, e quanto ao estado de emergência, importa refletir sobre o sentido do fundamento último do estado de emergência, o qual se reconduz, como salientámos, ao restabelecimento da normalidade constitucional, que se pressupõe momentaneamente alterada, in casu, por uma situação de calamidade pública. Sem prejuízo de nos continuarmos a rever nesta conformação do estado de emergência, a verdade é que, em contexto pandémico, a respetiva declaração se destinou (menos a repor, a defender ou mesmo a preservar (33) a ordem constitucional em perigo ou a «normalidade constitucional» ${ }^{12}$, e mais) a constituir um título habilitador para a ação administrativa, um respaldo normativo para as medidas de limitação (lato sensu) de direitos, liberdades e garantias consideradas necessárias para combater a emergência de saúde pública decorrente da COVID-19. O continuum com uma solução mais próxima do texto e da teleologia do artigo $19 .^{\circ}$ apenas se alcançará se optarmos por uma aceção ampla da anormalidade constitucional subjacente ao estado de sítio/emergência, enquadrando no conceito de calamidade pública um acontecimento externo e natural (hoc sensu, não dominado pelo homem), suscetível de afetar toda a comunidade, e que envolve a criação (previsível ou consumada) de um perigo especial e anormalmente grave para um bem jurídico-constitucional (fundamental?) - in casu, a saúde pública e a vida humana -, o qual se revela suscetível de permitir a mobilização de medidas excecionais no quadro do instituto em análise. Resta, contudo, saber se uma interpretação tão fluida ${ }^{13}$ se revelará compatível com a excecionalidade subjacente ao instituto...

Ademais, apesar de o estado de emergência se encontrar concebido constitucionalmente para vigorar durante um período temporal curto, uma tão prolongada pandemia, com consequências sanitárias (mas também económicas) tão extensas, tem acabado por exigir sucessivas renovações - o que, não deixando de representar uma garantia relevante contra o abuso da figura e, por conseguinte, contra a perpetuação incontrolada da suspensão do exercício de direitos (autorizada, a cada renovação, pelo

\footnotetext{
12 Enquanto «registo-chave» do regime jurídico-constitucional do estado de exceção (35).

${ }^{13}$ Mas também correspetiva da "indeterminação por vaguidade" que predica o conceito de calamidade pública (20).
} 
se sublinhar que, sem prejuízo das diferenças que hoje nos apartam desta realidade, as situações de exceção e as respostas encontradas para a respetiva reação acabam por, volente nolente, implicar uma preponderância do Executivo, mesmo quando (como sucede entre nós) a competência para a declaração (do estado de emergência) se encontra cometida ao Chefe de Estado dotado de legitimidade democrática direta (20).

I. Desde logo, a execução nacional da declaração do estado de emergência encontrase cometida ao Governo (cf. artigo $17 .^{\circ}$ do RESEE), enquanto órgão superior da Administração Pública, em consonância com a ideia segundo a qual o poder executivo se caracteriza por um exercício diuturno e detém os meios necessários para enfrentar as crises (20). Repare-se ainda que a CRP mobiliza a expressão "autoridades" (cf. artigo $19 .^{\circ}, \mathrm{n} .{ }^{\circ} 8$ recuperado pelo artigo $19 .^{\circ}$ do RESEE) para designar as entidades competentes para adotarem as providências adequadas e necessárias ao pronto restabelecimento da ordem constitucional - o que, por sua vez, remete para a Administração (20) [naturalmente, sob a direção (hoc sensu) do Governo] um papel determinante logo na conformação das medidas, mas também na respetiva execução. O facto de a lei impor um dever de informação ao Presidente da República e à Assembleia da República incidente sobre as medidas de execução não afasta o protagonismo governamental, mas enfatiza o relevo da responsabilização política deste órgão perante aqueloutros.

Assume, neste horizonte, uma importância não despicienda a figura do regulamento administrativo: eis a natureza jurídica que assumem as normas (ou, pelo menos, a maioria delas) constantes dos diversos decretos governamentais que vêm concretizando a declaração do estado de emergência emanada pelo Presidente da República. Esta forma de ação administrativa exerce aqui funções diferenciadas (8) (44): uma função de execução, enquanto instrumento normativo imprescindível para atuar a disciplina jurídica decorrente da declaração do estado de exceção constitucional, ou, eventualmente, e dentro de estreitos limites, uma função de dinamização, consubstanciando-se como um «direito administrativo

\footnotetext{
âmbito territorial das Províncias Ultramarinas, permitia que o Executivo, não estando reunidas as Cortes, decretasse as medidas legislativas consideradas urgentes, ou que o Governador Geral da Província decretasse as "providências indispensáveis para acudir a uma necessidade tão urgente que não [pudesse] esperar pela decisão das Cortes ou do Governo", sem prejuízo de, nos termos do $\S 3 .^{\circ}$ do mesmo preceito, o Governo, em ambas as hipóteses, submeter às Cortes os diplomas em causa). Recorde-se que o recurso à emanação de legislação por decreto - e, por conseguinte, através de decretos ditatoriais - acabaria por gerar o costume de os cumprir enquanto o legislador os não revogasse - um costume sancionado pela própria atuação das Cortes que, a posteriori e como regra, adotavam os atos legislativos, nos termos do quais se mantinham em vigor as medidas constantes dos decretos ditatoriais, legitimando-as, pois, com (pelo menos) uma aparência de legalidade (38).
} 


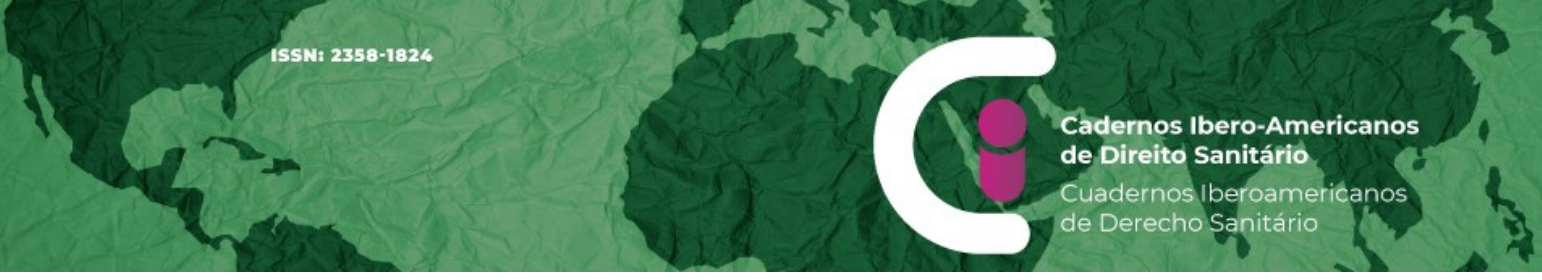

de complemento» ${ }^{18}$ da declaração do estado de sítio ou do estado de emergência. Concebendo-se como mecanismo jurídico que desenvolve e completa aquele diploma, o regulamento encontra na declaração do estado de emergência (20) (45) $)^{19}$ e no RESEE a delineação da competência objetiva para a respetiva emissão, podendo a competência subjetiva (do Governo) reconduzir-se à norma geral constante da alínea $g$ ) do artigo $199 .^{\circ}$ da CRP em conjugação com o citado artigo $17 .^{\circ}$ do RESEE.

Não ignoramos os delicadíssimos problemas que, sob uma ótica jurídicoconstitucional, de podem suscitar no que tange à delineação deste poder regulamentar, em especial $^{20}$, nas questões atinente aos direitos, liberdades e garantias, enquanto matéria de reserva de lei.

\footnotetext{
18 A doutrina alemã refere-se à existência de um administratives Ergänzungsrecht, para designar a específica relação entre lei e regulamento (40) (41) (42) (43) - expressão que, mutatis mutandis, adaptámos ao presente contexto.

${ }^{19}$ Neste sentido, podemos também acolher a ideia de que o desenvolvimento do estado de exceção convive com uma «normatividade partilhada» entre a declaração presidencial e os atos de regulamentação do Governo (46).

${ }^{20}$ Mas não só sob este ponto de vista: uma questão que vem suscitando controvérsia na doutrina e na jurisprudência portuguesas consistiu na circunstância de, num primeiro momento, os decretos governamentais que promoviam a execução do estado de emergência preverem que a violação da obrigação de confinamento implicava a prática de um crime de confinamento. Referências similares (e, por conseguinte, igualmente equívocas) constavam do artigo $5 .^{\circ}$ do Decreto do Presidente da República n. ${ }^{\circ} 17-A / 2020$, de 2 de abril, e do Decreto do Presidente da República n. ${ }^{\circ} 20-A / 2020$, de 17 de abril. Sem prejuízo das reflexões mais aprofundadas que o tema merece, parece-nos que a defesa da inconstitucionalidade (orgânica, procedimental e formal) da norma regulamentar terá assentado no equívoco de que a norma penal incriminadora se encontraria consagrada num regulamento - o que, a ser assim, implicaria a respetiva inconstitucionalidade por violação da reserva de competência legislativa da Assembleia da República [cf. artigo $165 .^{\circ}$, n. $^{\circ} 1$, alínea $c$ ), da CRP]. Ora, e pese a deficiente técnica normativa (sempre questionável quando repete - e, por consequência, "degrada" - para ato hierarquicamente inferior disposições constantes de ato dotado de nível hierárquico inferior), os diplomas em causa pretendiam apenas "recordar" a aplicação do disposto no artigo $7 .^{\circ}$ do RESEE, cujo âmbito se não se circunscreveria à violação da obrigação de confinamento, envolvendo a ofensa de todas as imposições constantes do próprio RESEE, do decreto presidencial de declaração do estado de emergência e do decreto governamental que o executava. Mais problemático se poderá revelar, contudo, o cumprimento do princípio da determinabilidade e a exigência de densidade normativa acrescida em matérias de reserva de lei...No apontado sentido da inconstitucionalidade se orientou, $v$. $g$., o Acórdão do Tribunal da Relação de Guimarães de 09.11.2020, P. 119/20.1PBCHV.G1, rejeitando ainda (sobretudo com fundamento na história legislativa) que aquele preceito legal pudesse ter como destinatários outros que não os titulares de poderes públicos (47). Mas nem toda a doutrina se pronuncia no mesmo sentido (48), e algumas perspetivas põem a tónica noutros problemas como o da determinabilidade. Adotando uma visão diversa se havia pronunciado já André Lamas Leite, "Desobediência em Tempos de Cólera": A Configuração deste Crime em Estado de Emergência e em Situação de Calamidade», in: Revista do Ministério Público, n. ${ }^{\circ}$ especial COVID-19, 2020, pp. 169 e s.. Colocando a tónica no problema da determinabilidade (49). Sobre esta matéria, mas partindo de um outro prisma (o da adequação do crime de desobediência para a proteção da saúde pública e a questão do bem jurídico protegido), $v$. as desafiantes considerações de Susana Aires de Sousa (50): as conclusões da Autora apenas reforçam a ideia - que desenvolvemos em texto - da tendencial inadequação do instituto do estado de exceção constitucional para fazer frente a crises pandémicas. Muito recentemente, o Tribunal Constitucional (no Acórdão n. ${ }^{\circ} 352 / 2021$, de 27 de maio, tirado por maioria) apreciou a constitucionalidade de um preceito análogo aos que nos referimos (artigo 43. $.^{\circ},{ }^{\circ}{ }^{\circ}$, do Decreto n. ${ }^{\circ} 2-\mathrm{B} / 2020$, de 2 de abril, na parte em que agravou em um terço dos limites mínimo e máximo da moldura penal do crime de desobediência, na modalidade aplicável nos autos, operado pela norma sindicada). Invocando a circunstância de a norma constar de um decreto governamental emanado em execução da declaração presidencial de estado de emergência, aquela Alta Jurisdição entendeu que a mesma não padeceria de inconstitucionalidade por violação da reserva relativa da competência legislativa da Assembleia da República. Neste sentido, a declaração de estado de emergência promove um alargamento das competências do Executivo também em matéria de direitos, liberdades e garantias, pois que a adoção das providências necessárias ao restabelecimento da ordem constitucional consubstancia uma competência governamental "diretamente fundada no n. 8 do artigo $19 .^{\circ}$ da Constituição". Assim, não se considera que tal implique uma afetação das "regras constitucionais relativas à competência e ao funcionamento dos órgãos de soberania", vedada pelo n. ${ }^{\circ} 7$ do artigo $19 .^{\circ}$ da Constituição, porquanto "este poder normativo é absolutamente excecional e não inibe o uso regular do poder legislativo normal" (itálicos no original).
} 
II. Além disso, também a declaração de situação de calamidade, baseada na LBPC, reforçou esta centralidade do Governo (36). Em situações de emergência grave em saúde pública, particularmente perante situações de calamidade ou catástrofe, o membro do Governo responsável pela área da saúde toma as medidas necessárias de exceção que forem indispensáveis, coordenando a atuação dos serviços centrais do Ministério com as instituições e serviços do SNS e as autoridades de saúde de nível nacional, regional e municipal (cf. artigo $5 .^{\circ}, \mathrm{n} .^{\circ} 4$, do Decreto-Lei n. ${ }^{\circ} 82 / 2009$ ). Na mesma linha se orienta, como sublinhámos, a citada Lei n. ${ }^{\circ} 81 / 2009$, que, em caso de emergência em saúde pública, confere poderes administrativos excecionais ao membro do Governo responsável pela área da saúde (cf. artigo 17. ${ }^{\circ}$ ). Neste horizonte normativo, os problemas práticos reconduziramse à circunstância de, no âmbito da designada primeira vaga, algumas das medidas adotadas como execução do estado de emergência se haverem prolongado, posteriormente ao abrigo da situação de calamidade ou do sistema de vigilância em saúde pública (51).

\section{Os "remédios" dos direitos fundamentais}

A fixação constitucional e legal de pressupostos e condições de estados de exceção indica nitidamente que não estamos aqui no âmbito de uma zona fora do princípio da juridicidade, mas, pelo contrário, que os poderes públicos se encontram a agir ainda no quadro de um Estado de direito, também em consonância com a conceção da normatividade e da organização próprias da excecionalidade como meios de garantia constitucional (31), e, portanto, no quadro de um "direito normativo-constitucionalmente conformado" (34). Estamos, pois, muito distantes do aforismo necessitas non habet legem (sed ipsa sibi facit legem), atribuída a Publilius Syrus, dramaturgo romano do século I a. C. (52), e numa aproximação significativa à ideia segundo a qual o reconhecimento da existência de estados de exceção normativo-constitucionalmente configurados pressupõe o afastamento de sistemas de natureza ditatorial (hoc sensu) (20). Destarte, não surpreende que, sem prejuízo do papel conferido à Administração, os tribunais surjam não só como "guardiães da Constituição", mas também como verdadeiros defensores da juridicidade (ou do Estado de direito) (20) (21) (39) (53) em situações de excecionalidade constitucional e/ou administrativa. A garantia da tutela jurisdicional efetiva - mesmo nas hipóteses mais gravosas em que ocorre a declaração do estado de sítio e do estado de emergência encontra-se expressamente confirmada pelo legislador, que prevê o acesso aos tribunais 
para defesa dos direitos, liberdades e garantias lesados ou ameaçados de lesão por quaisquer providências inconstitucionais ou ilegais (cf. artigo $6 .^{\circ}$ do RESEE).

Salvaguardadas as hipóteses em que o litígio emerge de uma (eventual) violação do direito à liberdade, e, por conseguinte, se reconduz à reação contra uma detenção ilegal, os "remédios" utilizados para o controlo da juridicidade da atuação dos poderes públicos no que tange à afetação dos direitos fundamentais relevam, sobretudo, da Justiça Administrativa e/ou da Justiça Constitucional. Entre nós (mas à semelhança do que sucede em outros ordenamentos), são já alguns (embora não muitos) os processos que, tendo chegado ao Tribunal Constitucional ou ao Supremo Tribunal Administrativo, se debruçaram sobre a constitucionalidade/legalidade das medidas adotadas no contexto da pandemia que contendem com direitos fundamentais.

Uma análise preliminar da jurisprudência disponível permite antecipar quatro reflexões.

Primo, e sem prejuízo de, no que respeita à jurisdição administrativa, não dispormos de dados sobre os tribunais de primeira instância, afiguram-se, em termos comparativos ( $v$. g., com os casos alemão ${ }^{21}$ e francês), relativamente escassos os processos intentados para defesa dos direitos fundamentais. Não nos parece, porém, poder inferir necessariamente deste dado que as medidas adotadas não suscitem dúvidas sobre a respetiva constitucionalidade (ou legalidade) - como, aliás, decorre da aposição de declarações de voto em dois dos Acórdãos.

Secundo, sem prejuízo dos dois arestos do Tribunal Constitucional tirados em recursos de constitucionalidade, foram dirigidos à Justiça Administrativa os processos para a tutela de direitos fundamentais, em particular para a intimação para a proteção de direitos, liberdades e garantias - cujas decisões, fazendo jus à qualificação como processo urgente, foram proferidas de modo célere, traduzindo um autêntico cumprimento do direito de tutela jurisdicional efetiva e consolidando a função dos tribunais de defensores dos direitos fundamentais e do Estado de direito. Destarte, e não obliterando que, no ordenamento português, todos os tribunais são órgãos de controlo da constitucionalidade das normas (e, por conseguinte, defensores dos direitos fundamentais), parece inegável o papel preponderante desempenhado pela jurisdição administrativa, partilhando o protagonismo assumido tradicionalmente pela Justiça Constitucional (sobretudo, em ordenamentos onde

${ }^{21} \mathrm{Na}$ Alemanha alude-se à existência de mais de mil (!) decisões judiciais (54). 
Ihe cabe o julgamento de "queixas constitucionais" e "recursos de amparo"). Neste conspecto, é de aplaudir uma interpretação ampla dos pedidos suscetíveis de formulação no âmbito da intimação para a proteção de direitos, liberdades e garantias, em consonância quer com o sentido garantístico emergente do $n .^{\circ} 5$ do artigo $20{ }^{\circ}$ da CRP, quer com a perspetiva (já defendida, em momento anterior, pelo Supremo Tribunal Administrativo) segundo a qual este meio processual corresponde à "consagração de um direito constitucional de amparo a efetivar através das vias judiciais normais" - o que implica acolher igualmente 22 (8) (44) o controlo da validade de regulamentos administrativos, incluindo da respetiva constitucionalidade, desde que em causa não esteja uma declaração de inconstitucionalidade com força obrigatória geral (mas apenas com efeitos circunscritos ao caso).

Tertio, a apreciação da juridicidade das medidas apontou para a mobilização de princípios normativos fundamentais, como sucedeu, paradigmaticamente, com o princípio da proporcionalidade ou com o princípio da igualdade. Todavia, uma tal convocação também acabou por revelar algumas das perplexidades subjacentes aos juízos valorativos que pressupõem e as debilidades emergentes dos seus entendimentos tradicionais (54) (56).

Quarto, a possibilidade de confronto com experiências jurídicas e jurisdicionais estrangeiras e a existência de um diálogo interjurisdicional (mesmo que não formalizado e decorrente apenas da convocação de decisões proferidas pelos tribunais estrangeiros em matérias similares) representam um passo determinante para, à imagem da espiral metodológica, a redensificação do Estado de direito, e constituem arrimos relevantes para a aferição da juridicidade das medidas adotadas e, sobretudo, para a afinação da retórica argumentativa.

Ainda assim, embora frutífero, o reconhecimento da internormatividade e a convocação cruzada de experiências normativas diversas (internacional e supranacional) não pode consubstanciar um argumento (e, muito menos, uma base jurídica) para modificar a essência dos princípios fundamentais que regem a Administração Pública - em particular, do princípio da legalidade. Na verdade, a convocação abstrata do direito europeu ou do direito internacional (hard ou soft law) não pode escamotear a específica conexão entre o princípio do Estado de direito e o princípio democrático - que constitui, a final, o punctum saliens da exigência de base legal para a atuação administrativa. Recorde-se, desde já, que,

\footnotetext{
${ }^{22}$ Cf. agora Acórdão do STA, 10.09.2020, P. 088/20.8BALSB, numa solução já saudada pela doutrina (55).
} 


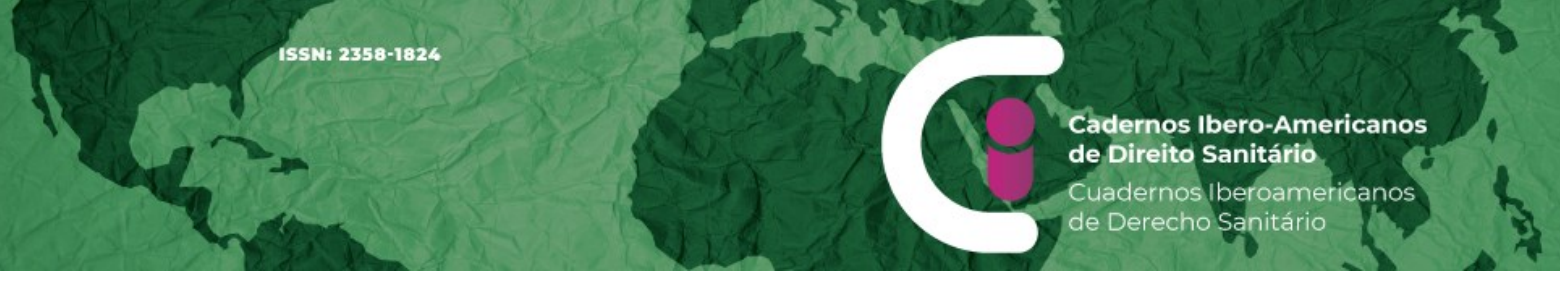

logo em Montesquieu, a democracia exprime o autogoverno dos cidadãos e verte-se positivamente na lei - o que aproxima as exigências de sentido do princípio democrático do relevo conferido ao princípio da legalidade e ao seu relacionamento com a constitucionalidade. E uma conceção diversa, que pretenda dar por cumprido o princípio da legalidade da Administração (em particular, os princípios da precedência de lei e, quando estão em causa direitos, liberdades e garantias, da reserva de lei) relativamente a determinada medida administrativa, através da mobilização de uma "internormatividade técnica", ou do confronto com soluções análogas de direito de outros Estados-Membros da União Europeia, colide com o próprio texto constitucional, se tais elementos se não conjugarem com uma habilitação legal prévia ${ }^{23}$ (princípio da precedência de lei) - habilitação essa que, tratando-se de matéria reservada, há de constar de uma lei, dotada de um grau de densidade normativa mais elevado, em virtude de àquela se encontrar constitucionalmente devolvida a respetiva normação primária (princípio da reserva de lei) ${ }^{24}$ (55) (24).

\section{Considerações finais (ou preliminares?): a pandemia e o regresso das reflexões seminais do direito público}

As considerações anteriores demonstram que as projeções jurídicas da pandemia se volvem, a final, num "teste de esforço" do próprio Estado de direito, cuja defesa assume

\footnotetext{
${ }^{23}$ Desde logo, tratando-se de regulamento administrativo, o n..$^{\circ} 7$ do artigo $112 .^{\circ}$ da Constituição obriga, como se sabe, à identificação da lei que confere a competência objetiva e subjetiva para a sua emissão - ou, sendo caso disso, o regulamento europeu ou a norma de direito internacional diretamente aplicável (8) (57).

24 Trata-se de uma perspetiva que não colide com a nossa defesa do constitucionalismo administrativo (cf., supra, 2) ou mesmo com o reconhecimento (que vimos propugnando) de uma função de dinamização da ordem jurídica conferida aos regulamentos administrativos, também em matéria reservada (8) - na senda da proposta de Vieira de Andrade (58), para quem, ainda quando a reserva não se circunscreve às bases ou ao regime geral, a mesma reveste caráter não integral ou total, admitindo intervenções normativas da Administração. Com efeito, a solução passa por distinguir, neste horizonte, entre normação principal ou essencial e normação acessória ou periférica, já que o problema da reserva de lei não prescinde da sua compreensão numa dimensão vertical enquanto reserva de função. Não se anunciando possível alicerçar constitucionalmente um conceito material de lei, torna-se, no entanto, viável a defesa de um modelo tipológico de distinção material entre as funções legislativa e administrativa, em termos que permitam uma intervenção primária regulamentar em matéria reservada sem atingir os aspetos essenciais ou fundamentais da mesma (normação principal ou essencial), que constituem o núcleo típico da função legislativa e que, por esse motivo, vão exigir do legislador uma aplicação especialmente rigorosa do princípio da determinabilidade das normas, reduzindo concomitantemente a discricionariedade regulamentar - tendo ainda em conta que o sentido atribuível a cada uma das normas que preveem as matérias reservadas não se revela igual em todas elas, nem mesmo quando as mesmas são literalmente idênticas. Em matéria reservada, a admissibilidade de os regulamentos desempenharem uma função de dinamização da ordem jurídica depende de o ordenamento dispor de densificação legislativa suficiente (esgotante da disciplina principal) que autorize a lei habilitante a limitar-se à mera definição da competência objetiva e subjetiva para a sua emissão. Os regulamentos então emitidos não constituem o resultado de qualquer «cheque em branco» passado à Administração, mas o desenvolvimento de princípios ou normas gerais (os aspetos principais da disciplina jurídica em causa) fixados em legislação anterior. Quer dizer, e numa perspetiva que permita aferir da constitucionalidade quer da lei que opera a remissão, quer dos regulamentos nestes termos emitidos, mais do que perguntar qual o conteúdo da lei habilitante, o intérprete deverá perspetivar o ordenamento legislativo no seu todo e avaliar se o grau de intervenção legislativa na matéria se revelava (ou não) suficientemente denso para permitir uma intervenção regulamentar sobre a mesma.
} 
especial relevo em momentos de crise. A experiência atual rasga caminhos para reflexões ulteriores, quer a nível do Direito Constitucional, quer no plano do Direito Administrativo reflexões essas que retomam justamente os temas que, desde sempre, vêm agitando o direito público.

Por um lado, a relativa incipiência de instrumentos juridicamente admissíveis de resposta à pandemia gerou alguma indefinição no que tange à forma e ao grau de afetação dos direitos - entendidos como um dos pilares do Estado de direito. Esta crise veio atestar que, também no plano do(s) direito(s), a preparedness representa um aspeto primordial para a evolução dos regimes jurídicos, impondo-se uma reflexão e um aprimoramento, a posteriori, sobre a matéria ${ }^{25}$. Neste contexto, ressalta-se, do lado europeu (e, portanto, num horizonte jurídico-cultural mais próximo que as experiências asiáticas), a Infektionsschutzgesetz alemã (60) que, tendo entrado em vigor já em 2001, estabelecia um quadro normativo relativamente sólido para situações análogas (embora sem a dimensão da COVID-19), mas que, ainda assim, teve de sofrer alterações significativas durante a pandemia, entre as quais a introdução de um estado de "situação epidemiológica de importância nacional" (epidemische Lage von nationaler Tragweite) (61), caracterizada pela existência de um sério perigo para a saúde pública em toda a Alemanha, em virtude de a OMS haver declarado uma emergência de saúde pública de importância internacional e de estar iminente a importação para a Alemanha de uma doença contagiosa ameaçadora, ou em virtude de estar iminente ou já ter ocorrido uma propagação dinâmica de uma doença contagiosa ameaçadores em vários Länder (cf. § 5, n. ${ }^{\circ}$ ). Cabe ao artigo § 28a apresentar um elenco (não taxativo) de medidas (restritivas de direitos) necessárias a conter a disseminação da doença, as quais constarão da declaração de "situação epidemiológica de importância nacional", da competência do Bundestag. Embora, em geral, positivo, também este diploma não deixa de suscitar dúvidas de constitucionalidade, em especial, por força dos poderes bastante extensos que, ao cabo e ao resto, acaba por conferir ao Executivo ( $v$., por excelência, $\left.\S 5, n .^{\circ} 2\right)$.

\footnotetext{
${ }^{25} \mathrm{O}$ ordenamento jurídico português esteve quase a lograr uma posição dianteira nesta matéria: na verdade, a Base XIII do Projeto de Proposta de Lei de Bases da Saúde (59) previa o desenvolvimento e a implementação de instrumentos de observação em saúde, nomeadamente de monitorização e vigilância epidemiológica, assim como o desenvolvimento de um sistema de saúde pública que permitisse identificar, avaliar, gerir e comunicar situações de risco relativamente a doenças transmissíveis e outras ameaças à saúde pública, e a preparação e atualização sistemáticas de planos de contingência face a situações de emergência ou de calamidade pública, determinando as medidas temporárias necessárias à proteção da saúde pública. Infelizmente, nenhum destes aspetos acabaria por transparecer na Base 10 da nova LBS..
} 
Repare-se que, a ser elaborada, em qualquer sistema jurídico, uma lei de proteção epidemiológica ou de emergência sanitária, a mesma exigirá não só uma adequada articulação com o sentido da existência de um estado de exceção constitucional com fundamento em calamidade pública (ou instituto análogo), como também uma reflexão e uma ponderação em matéria de conformação/limitação/restrição de direitos fundamentais, sobretudo, direitos, liberdades e garantias. Além de problemas específicos relacionados com a conveniência ou mesmo a legitimidade da interferência do direito no exercício da medicina (como sucede, v. g., nas questões relativas à triagem de doentes (62)), adivinham-se problemas que tocam o próprio âmbito de proteção de direitos fundamentais (e, correlativamente, do desenho das respetivas hipóteses de restrição) como sucederá, por exemplo, com o direito à intimidade da vida privada e à autodeterminação informativa (e as questões - muito diversas entre si - decorrentes quer da eventual obrigatoriedade da utilização de aplicações de geolocalização e de rastreio de contactos (63), quer do registo e publicitação das pessoas vacinadas, nomeadamente através da emissão de "passaportes de imunidade COVID-19" ou "certificados sanitários" (64), quer do controlo de temperatura corporal), ou o direito à integridade física (e questões relacionadas com a vacinação obrigatória), ou mesmo a liberdade de iniciativa económica ou a liberdade de empresa (e as soluções relacionadas com a gestão de redes de comunicação e do respetivo tráfego, de modo a dar prioridade à prestação de serviços críticos). A estes problemas associam-se ainda as dimensões materiais relacionadas com a observância das exigências de sentido do princípio da proporcionalidade, ou as dimensões formais atinentes ao princípio da determinabilidade das normas ou da densidade normativa acrescida ${ }^{26}$ em todas as disposições que toquem direitos, liberdades e garantias, enquanto matéria incluída na reserva de lei.

Por outro lado, a centralidade assumida pelo Executivo exige que se confira um influxo novo (ou renovado) ao autocontrolo da juridicidade da sua atuação; no campo em que nos movemos, colhe especial sentido a necessidade de consciencialização de que a Administração Pública é um ator responsável pela realização da Constituição e dos direitos fundamentais.

\footnotetext{
${ }^{26}$ Já que, na síntese lapidar de Siegel (56) quanto mais intensa for a intervenção nos direitos fundamentais, mais precisa e diferenciada deve ser a norma, sendo de evitar restrições maciças de direitos ao abrigo de cláusulas gerais "magras" (dünne).
} 
O autocontrolo não significa, porém, a desvalorização de outros instrumentos de garantia, imprescindíveis para tornar admissível aquela centralidade. Recorde-se que, tradicionalmente (65), a proteção dos direitos contra o Estado (Governo e Administração) se efetuava quer, em geral, mediante o acesso aos tribunais, quer, em especial, através do instituto da responsabilidade civil das entidades públicas.

Assim, e quanto ao primeiro ponto, constituindo os tribunais a clef de voûte do sistema de garantia dos direitos em situação de exceção, através da jurisdição constitucional e/ou administrativa, urge desenvolver uma reflexão renovada, à luz da experiência ocorrida entre nós, mas sem perder de vista os contributos propiciados pela comparação jurídica, acerca dos remedies disponíveis. Talvez seja este o momento de avaliar em que medida continua (ou não) a revelar-se adequada a ausência de previsão de uma ação constitucional de defesa. Trata-se de uma temática que, havendo constituído objeto de discussão durante a segunda revisão constitucional ${ }^{27}$, vem-se tornando controversa no seio da doutrina nacional, porquanto a Justiça Constitucional, em virtude de incidir apenas atos normativos, deixa de fora as ofensas a direitos fundamentais decorrentes de atos administrativos, sentenças judiciais ou outros atos individuais e concretos emanados por poderes públicos (67) (68). Naturalmente, a Constituição não se revela indiferente a este problema: daí que o n. ${ }^{\circ} 5$ do artigo $20 .^{\circ}$, aditado pela revisão constitucional de 1997 , tenha previsto a criação de um processo urgente contra ameaças ou violações de direitos, liberdades e garantias pessoais - o que foi concretizado mediante a criação, no seio da Justiça Administrativa, e com um escopo mais amplo, da intimação para a proteção de direitos, liberdades e garantias, precisamente o processo ao abrigo do qual foram intentadas as várias ações destinadas a reagir contra as medidas de combate à pandemia. Todavia, e mesmo considerando a existência desta intimação urgente e o relevo assumido pelos tribunais ordinários (in casu, dos tribunais administrativos) para a promoção dos direitos fundamentais (69), a falta de competência do Tribunal Constitucional para apreciar atuações individuais e concretas vulneradoras de direitos fundamentais irá, com probabilidade, despertar cogitações adicionais sobre esta matéria (70).

No que tange à dimensão da responsabilidade civil $^{28}$, também esta sofreu, durante a pandemia, vicissitudes que suscitaram perplexidades. Se, quer o estado de exceção

\footnotetext{
${ }^{27} \mathrm{E}$ também tendo sido introduzida em Macau, quando estava ainda sob administração portuguesa (66).

${ }^{28}$ Aqui concebido à luz da formulação conceptual ampla desenhada por Gomes Canotilho (71), i. e., desvinculando a responsabilidade civil (delitual) da antijuridicidade, pondo a tónica na função da ressarcibilidade dos danos (e não numa
} 


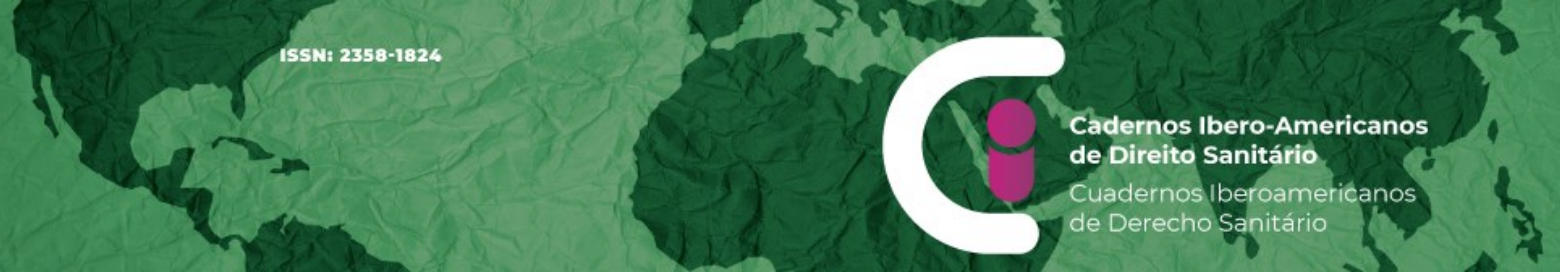

constitucional da responsabilidade civil do Estado ${ }^{32}$, esvaziando, em estado(s) de necessidade, o princípio da igualdade dos encargos públicos e o sentido de justiça, que constitui o fundamento último do instituto (57). O princípio da responsabilidade, hoje plasmado legislativamente no artigo $16 .^{\circ}$ do CPA, aliado à consideração de que os atos praticados ao abrigo de estado(s) de necessidade dão lugar ao pagamento de uma indemnização, quando geradores de danos (cf. também artigo $3 .^{\circ}, n .^{\circ} 2$, do CPA), ditam, pois, a solução inversa e impõem a aplicação do regime regra, determinando que eventuais situações de desigualdade geradoras de danos motivadas em razões de interesse público sejam compensadas mediante o pagamento de uma indemnização (71).

Em suma, considerando que a pandemia e as respetivas consequências sanitárias, mas, sobretudo, económicas constituem um desafio social normativamente relevante, as mesmas exigirão certamente reflexões que importarão mutações significativas no desenvolvimento do direito público, as quais, todavia, não poderão colocar em xeque as exigências de sentido dos princípios estruturantes do Estado de direito, da democracia e da socialidade.

\section{Referências}

1.Vera-Cruz E. O Direito Após a Pandemia COVID-19: Os Binómios Fundamentais. Revista da Faculdade de Direito de Lisboa. 2020;66(1):187-205.

2.Estorninho MJ, Macieirinha T. Direito da Saúde. Lisboa: Universidade Católica Editora; 2014. 312 p.

3.Moniz ARG. O Administrative Constitutionalism: Resgatar a Constituição para a Administração Pública. In: Estudos em Homenagem ao Prof. Doutor José Joaquim Gomes Canotilho - IV. Coimbra: Coimbra Editora; 2012. p. 387-420.

4.Lee SZ. Race, Sex, and Rulemaking: Administrative Constitutionalism and the Workplace, 1960 to the Present. Virginia Law Review. 2010;96:799-886.

\footnotetext{
32 Se se revela mais ou menos pacífica a possibilidade de extrair do artigo $22 .^{\circ}$ um direito de natureza análoga aos direitos, liberdades e garantias, no que respeita à responsabilidade por facto ilícito (como tal, dotada de aplicabilidade direta), algumas reticências ainda se vislumbram relativamente a tal qualificação no que tange à responsabilidade por facto lícito ou à indemnização pelo sacrifício. Assim acontece, paradigmaticamente, com Gomes Canotilho e Vital Moreira (35), e não obstante o reconhecimento dogmático de um «superconceito» de responsabilidade civil extracontratual em sentido amplo, entendem que o artigo $22 .^{\circ}$ não abrange a responsabilidade por atos lícitos, sem que tal signifique, porém, a exclusão constitucional de outros institutos indemnizatórios ou de compensação de danos emergentes de atos do poder público, desde logo com fundamento no princípio da igualdade perante os encargos públicos. Em sentido próximo, se inclina também Jorge Miranda (32) (78). Acentua igualmente Rui Medeiros (79) que, embora se não retire da norma constante do artigo $22 .^{\circ}$ o dever de indemnização por factos lícitos, a existência de um direito (constitucional) geral à reparação dos danos decorrentes de atuações públicas, este decorre do princípio do Estado de direito. Paulo Otero (80) considera já que o artigo $22 .^{\circ}$ consagra um direito de natureza análoga aos direitos, liberdades e garantias, (embora o Autor circunscreva, no que à responsabilidade por facto lícito concerne, o âmbito do artigo $22 .^{\circ}$ à lesão de direitos não patrimoniais, inclui a responsabilidade por facto lícito por sacrifício de direitos patrimoniais privados no $n .{ }^{\circ} 2$ do artigo $62 .^{\circ}$ da CRP).
} 


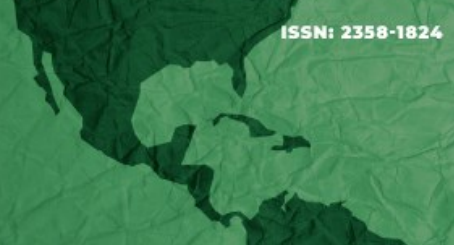

5.Fisher E, Harding. The Precautionary Principle and Administrative Constitutionalism: The Development of Frameworks for Applying the Precautionary Principle. In: Fisher E, Jones, Schomberg, editores. Implementing the Precautionary Principle: Perspectives and Prospectives, Cheltenham: Elgar; 2006. 256 p.

6.Fisher E. Risk Regulation and Administrative Constitutionalism. Oxford/Portland: Hart Publishing; 2010. 256 p.

7.Moniz ARG. A Discricionariedade Administrativa: Reflexões a Partir da

Pluridimensionalidade da Função Administrativa. O Direito. 2012;144(3):599-651.

8.Moniz ARG. A Recusa de Aplicação de Regulamentos pela Administração com Fundamento em Invalidade: Contributo para a Teoria dos Regulamentos. Coimbra: Almedina; 2012. 901 p.

9.Metzger GE. Administrative Constitutionalism's Lessons. The Regulatory Review [Internet]. 2019 [citado em 27 fev 2021]. Disponível em https://www.theregreview.org/2019/12/16/metzger-administrative-constitutionalismslessons/

10.Caetano M. Manual de Direito Administrativo - vol. I. 10. ${ }^{a}$ ed. Coimbra: Almedina; 1999. $641 \mathrm{p}$.

11.Amaral DF. A Responsabilidade da Administração no Direito Português, Lisboa: Revista da Faculdade de Direito da Universidade de Lisboa. 1973;(23)separata.

12.Andrade JCV. A Responsabilidade por Danos Decorrentes do Exercício da Função Administrativa na Nova Lei sobre Responsabilidade Civil Extracontratual do Estado e Demais Entes Públicos. Revista de Legislação e de Jurisprudência. 2009;137(3951):360371.

13.Shaaban AN, Peleteiro B, Martins MRO. COVID-19: What Is Next for Portugal?. Frontiers in Public Health [Internet]. 2020 [citado em 27 fev 2021];8:1-8. Disponível em https://www.frontiersin.org/articles/10.3389/fpubh.2020.00392 doi:

10.3389/fpubh.2020.00392

14.Raposo VL, long MT. The Struggle Against CoViD-19 Pandemic in Macao. BioLaw Journal. 2020;n. ${ }^{\circ}$ especial 1:747-752.

15.Gouveia JB. Portugal e a COVID-19: Balanço e Perspetivas de uma Ordem Jurídica da Crise. Revista do Ministério Público. 2020;41(número especial COVID-19):93-106.

16. Otero P. Lições de Introdução ao Estudo do Direito: I vol. - 2. ${ }^{\circ}$ tomo. Lisboa: s.n. 1999. $380 \mathrm{p}$.

17.Brito MN. Modelos de Emergência no Direito Constitucional. E-Pública - Revista Eletrónica de Direito Público [Internet]. 2020 [citado em 27 fev 2021];7(1):6-26. Disponível em https://www.e-publica.pt/volumes/v7n1/pdf/a2n1v7.pdf 
31.Miranda J. Artigo 19. In: Miranda J, Medeiros R. (editores). Constituição Portuguesa Anotada - tomo I. 2. ${ }^{a}$ ed. Coimbra: Coimbra Editora; 2010, p. 405-414.

32.Miranda J. Manual de Direito Constitucional - tomo IV. $5 .^{\text {a }}$ ed. Coimbra: Coimbra Editora; 2012. 508 p.

33.Vaz MA. Lei e Reserva de Lei: A Causa da Lei na Constituição Portuguesa, Porto: Universidade Católica; 1992. 549 p.

34.Canotilho JJG. Direito Constitucional e Teoria da Constituição. 7.. ed., Coimbra: Almedina; 2003. 1522 p.

35.Canotilho JJG, Moreira V. Constituição da República Portuguesa Anotada - vol. I. 4. ${ }^{a}$ ed. Coimbra: Almedina; 2007. 1152 p.

36.Correia JA. As Patologias da Declaração do Estado de Calamidade e os Limites Constitucionais do Direito Administrativo da Pós-Emergência. Revista de Direito Administrativo - 9 Separata. Lisboa: AAFDL; 2020. 7 p.

37.Moniz ARG. Direito Administrativo: Textos e Casos Práticos Resolvidos. 3. a ed. Coimbra: Almedina; 2019. 468 p.

38.Araújo A, Brito MN. Os Alvores do Constitucionalismo Português na Governação de João Franco. Julgar. 2008;5:141-155.

39.Coimbra JD, Caldeira M, Serrão T. Direito Administrativo da Emergência. Coimbra: Almedina; 2020. 180 p.

40.Scheuing DH. Selbstbindungen der Verwaltung. In: Veröffentlichungen der Vereinigung der Deutschen Staatsrechtslehrer - 40, Berlin/New York: Gruyter; 1982. p. 153-186.

41.Rogmann A. Die Bindungswirkung von Verwaltungsvorschriften. Köln/Berlin/Bonn/München: Carl Heymanns Verlag; 1998. 260 p.

42. Ossenbühl F. Rechtsquellen und Rechtsbindungen der Verwaltung», in: Erichsen HU, Ehlers D (editores). Allgemeines Verwaltungsrecht. 12. ${ }^{a}$ ed., Berlin: Gruyter; 2002. p. 133227.

43.Ossenbühl F. Vorrang und Vorbehalt des Gesetzes. In: Isensee, Kirchhof (editores). Handbuch des Staatsrechts - V. 3. ${ }^{a}$ ed. Heidelber: C. F. Müller; 2007. p. 183-221.

44.Moniz ARG. Estudos sobre os Regulamentos Administrativos. 2. a ed. Coimbra: Almedina; 2016. 452 p.

45.Miranda J. Constituição e Pandemia - Breve Nota. Revista da Faculdade de Direito de Lisboa. 2020;66(1):45-62. 


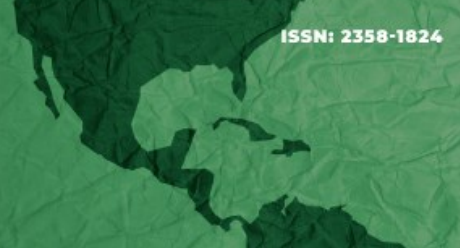

46.Lomba P. Constituição, Estado de Emergência e Administração Sanitária: Alguns Problemas. E-Pública - Revista Eletrónica de Direito Público [Internet]. 2020 [citado em 27 fev 2021];7(1):28-43. Disponível em https://www.e-publica.pt/volumes/v7n1/pdf/a3n1v7.pdf

47.Oliveira AA-Y. O(s) Crime(s) de Desobediência no Atual Estado de Emergência, em Especial no Domínio das Restrições ao Direito de Deslocação e Fixação - Breves Notas. In: Estado de Emergência - Covid-19: Implicações na Justiça [Internet]. Lisboa: CEJ; 2020 [citado em 27 fev 2021]. [p. 431-450]. Disponível em http://www.cej.mj.pt/cej/recursos/ebooks/outros/eb_Covid19.pdf

48.Leite AL. "Desobediência em Tempos de Cólera”: A Configuração deste Crime em Estado de Emergência e em Situação de Calamidade. Revista do Ministério Público. 2020;41(número especial COVID-19):165-191.

49.Magalhães VF. Reflexões sobre o Crime de Desobediência em Estado de Emergência. Julgar Online [Internet]. 2020 [citado em 27 fev 2021]:1-23. Disponível em http://julgar.pt/reflexoes-sobre-o-crime-de-desobediencia-em-estado-de-emergencia/

50.Sousa SA. Sobre a Proteção Penal da Saúde Pública em Tempos de Pandemia: "Isto já não é o que nunca foi”. Revista do Ministério Público. 2020;41(número especial COVID19):129-163.

51.Novais JR. Direitos Fundamentais e Inconstitucionalidade em Situação de Crise - A Propósito da Epidemia COVID-19. E-Pública - Revista Eletrónica de Direito Público [Internet]. 2020 [citado em 27 fev 2021];7(1):78-117. Disponível em https://www.epublica.pt/volumes/v7n1/pdf/a5n1v7.pdf

52.Koller. Not kennt kein Gebot: Entstehung - Verbreitung - Bedeutung eines Rechtssprichwortes. Wien: Lit Verlag; 2009. 240 p.

53.Botelho C. Os Estados de Exceção Constitucional: Estado de Sítio e Estado de Emergência. In: Gomes CA, Pedro R (editores), Direito Administrativo de Necessidade e de Excepção. Lisboa: AAFDL; 2020. p. 47-95.

54.Kaiser AB. The State of Exception under German Law and the Current Pandemic: Comparative Models and Constitutional Rights. E-Pública - Revista Eletrónica de Direito Público [Preprint]. 2020 [citado em 27 fev 2021].

55.Brito MN. Anotação ao Acórdão do STA, 1. ${ }^{a}$ Secção, de 10 de setembro de 2020, proferido no Processo n. ${ }^{\circ}$ 088/20.8BALSB. Revista de Direito Administrativo. 2021;10:129137.

56.Siegel T. Verwaltungsrecht im Krisenmodus. Neue Zeitschrift für Verwaltungsrecht. 2020;9: 577-583.

57.Otero P. Manual de Direito Administrativo - vol. I. Coimbra: Almedina; 2013. 596 p. 
58.Andrade JCV. Autonomia Regulamentar e Reserva de Lei. In: Estudos em Homenagem ao Prof. Doutor Afonso Rodrigues Queiró. Coimbra: Boletim da Faculdade de Direito;1984. p. 1-35.

59.Lei de Bases da Saúde: Materiais e Razões de um Projeto - Cadernos da Lex Medicinae n. ${ }^{\circ}$ 3. Coimbra: Instituto Jurídico | Faculdade de Direito da Universidade de Coimbra; 2018. 96 p.

60.Huster S, Kingreen T (editores). Handbuch Infektionsschutzgesetz. München: Beck; 2021. $426 \mathrm{p}$.

61.Gärditz KF. Die Feststellung einer Epidemischen Lage von Nationaler Tragweit - Ein Experiment Parlamentarischer Handlungsformen. Medizinrecht. 2020;38:741-744.

62.Hörnle T, Huster S, Poscher R (editores). Triage in der Pandemie. Tübingen: Mohr Siebeck; 2021. 372 p.

63.Raposo, VL. Que a Tecnologia Esteja Connosco Nestes Tempos de COVID-19 (Legitimidade da STAYAWAY COVID no Ordenamento Jurídico Português). Revista do Ministério Público. 2020;164:9-49.

64.Greely HT, COVID-19 Immunity Certificates: Science, Ethics, Policy, and Law. Journal of Law and the Biosciences. 2020;7(1):1-29.

65.Hespanha AM. Uma Monarquia Constitucional: A Constituição Monárquica Oitocentista. Lisboa: ed. Autor (Kindle); 2019.

66.Canotilho JJG. As Palavras e os Homens: Reflexões sobre a Declaração Conjunta Luso-Chinesa e a Institucionalização do Recurso de Amparo de Direitos e Liberdades na Ordem Jurídica de Macau. Boletim da Faculdade de Direito. 1994;70:107-131.

67.Novais JR. Direitos Fundamentais: Trunfos contra a Maioria. Coimbra: Coimbra Editora; 2006. 285 p.

68.Novais JR. Sistema Português de Fiscalização da Constitucionalidade: Avaliação Crítica. Lisboa: AAFDL; 2019. 195 p.

69.Morais CB. Justiça Constitucional - tomo II. 2. ${ }^{a}$ ed. Coimbra: Coimbra Editora; 2011. $1118 \mathrm{p}$.

70.Miranda J. Fiscalização da Constitucionalidade. Coimbra: Almedina; 2017. 399 p.

71.Canotilho JJG. O Problema da Responsabilidade do Estado por Actos Lícitos. Coimbra: policopiado; 1970-1971. $430 \mathrm{p}$.

72.Gomes, CA. Responsabilidade Civil Extracontratual do Estado e(m) Estado de Emergência: Dez Breves Notas. E-Pública - Revista Eletrónica de Direito Público [Internet]. 2020 [citado em 27 fev 2021];7(1):170-183. Disponível em https://www.epublica.pt/volumes/v7n1/pdf/a8n1v7.pdf 
73.Machado JB. Introdução ao Direito e ao Discurso Legitimador. Coimbra: Almedina; 1993. $388 \mathrm{p}$.

74.Ascensão JO. O Direito: Introdução e Teoria Geral. 13. ${ }^{a}$ ed. Coimbra: Almedina; 2005. $677 \mathrm{p}$.

75.Varela A. Das Obrigações em Geral - vol. I. 10. ${ }^{\text {a }}$ ed. Coimbra: Almedina, Coimbra; 2000. 962 p.

76.Martinez PR, Direito das Obrigações (Programa 2017/2018): Apontamentos, Lisboa: AAFDL; 2017. 317 p.

77.Barbosa MM. Lições de Responsabilidade Civil. Cascais: Principia; 2017. 448 p.

78. Miranda J. A Constituição e a Responsabilidade Civil do Estado. Revista Brasileira de Direito Constitucional. 2003;1:97-106.

79.Medeiros R. Artigo 22. ${ }^{\circ}$. In: Medeiros R. (editores). Constituição Portuguesa Anotada tomo I. 2. ${ }^{a}$ ed. Coimbra: Coimbra Editora; 2010, p. 468-485.

80.Otero P. Direito Constitucional Português - vol. I. Coimbra: Almedina; 2010. 303 p.

Moniz ARG. Promoção da saúde pública e proteção dos direitos fundamentais: a COVID-19 à luz das repercussões jurídico-constitucionais e jurídico-administrativas em Portugal. Cadernos Ibero-Americanos de Direito Sanitário. 2021 abr./jun.;10(2):183-210 